\title{
Outdoor exposure and vitamin D levels in urban children with asthma
}

\author{
Sonali Bose ${ }^{1 *}$, Patrick N Breysse ${ }^{1}$, Meredith C McCormack', Nadia N Hansel ${ }^{1}$, Robert R Rusher ${ }^{2}$, Elizabeth Matsui ${ }^{1}$, \\ Roger Peng ${ }^{1}$, Jean Curtin-Brosnan ${ }^{1}$ and Gregory B Diette ${ }^{1}$, for the Center for Childhood Asthma in the Urban \\ Environment
}

\begin{abstract}
Background: The inner-city pediatric population in the United States has a disproportionate burden of asthma. Recent attention has focused on the immunomodulatory role of vitamin D, which may be protective against disease morbidity. As the primary determinant of vitamin $D$ status in humans is exposure to sunlight, we aimed to determine if $25-\mathrm{OH}$ vitamin $\mathrm{D}$ levels in urban preschool children with asthma were low, influenced by time spent outdoors, and associated with asthma morbidity.

Methods: Serum 25-OH vitamin D levels were measured at baseline in a cohort of 121 inner-city children ages 2- 6 years with asthma in Baltimore, MD. Participants were followed longitudinally at 3 and 6 months to assess time spent outdoors, asthma symptoms through questionnaires and daily diaries, and allergic markers.

Results: In a predominantly black population of preschool children, the median $25-\mathrm{OH}$ vitamin D level was $28 \mathrm{ng} / \mathrm{mL}$ (IQR 21.2-36.9), with $54 \%$ of the children below the traditionally sufficient level of $30 \mathrm{ng} / \mathrm{mL}$ and $7.4 \%$ in the range associated with risk of rickets ( $<15 \mathrm{ng} / \mathrm{mL}$ ). The median time spent outdoors was 3 hours/day (IQR $2-4)$, and greater time spent outdoors was not associated with higher vitamin D levels. $25-\mathrm{OH}$ vitamin D did not show seasonal variation in our cohort $(p=0.66)$. Lower $25-\mathrm{OH}$ levels were correlated with higher lgE levels.

Conclusions: Urban African-American preschool children with asthma have high rates of vitamin D insufficiency, and increased outdoor exposure is unlikely to correct these low $25-\mathrm{OH}$ vitamin $\mathrm{D}$ levels. Repletion in this population may require dietary supplementation.
\end{abstract}

Keywords: Asthma, Vitamin D, Outdoor, Ultraviolet, Exposure

\section{Introduction}

Asthma morbidity is strikingly high among inner-city children in the United States, especially among AfricanAmericans [1,2]. While the reasons for this disparity are not entirely clear, several risk factors, including an urban environment enriched with air pollutants and unique allergens, lower socio-economic status, and poor diet, may predispose such children to more severe disease [2].

Of these factors, serum 25 hydroxy $(\mathrm{OH})$ vitamin $\mathrm{D}$ levels are disproportionately low in such populations [3-5] and may help to explain higher rates of asthma

\footnotetext{
* Correspondence: sbose7@jhmi.edu

'Johns Hopkins University, Baltimore, MD 21205, USA

Full list of author information is available at the end of the article
}

morbidity. Natural vitamin D production is determined by the UV component of sunlight which permits its cutaneous synthesis, and, given sufficient exposure to UV rays, results in currently accepted serum 25-OH D levels for humans. Cutaneous vitamin D synthesis, however, can be limited by darker skin pigmentation (as increased melanin competes for UV radiation), sunscreen use, clothing, and seasonal, atmospheric, and latitudinal factors that limit the availability of UV light [6]. Furthermore, dietary sources of vitamin D are limited to a few fortified foods [7], with African-American children found to have comparatively low D-rich intake [8]. Thus, while Americans generally spend the greater portion of their time indoors [9], inner-city children, especially African-Americans, may have additional risks for vitamin $\mathrm{D}$ deficiency due to risk factors that include having

\section{Biomed Central}


darker skin and a diet inadequate to compensate for deficiencies in production.

Furthermore, while vitamin D's role in protecting against growth retardation, skeletal deformities, rickets, and other bony diseases of childhood has been well established [10], emerging literature has supported its role in various chronic diseases, including asthma and allergy [11]. In children with asthma, those with lower serum 25-OH D have a higher risk of hospitalization $[12,13]$, greater use of anti-inflammatory medications $[12,14]$, more airway hyper-responsiveness $[12,13]$, and in adults, decreased sensitivity to corticosteroids [15]. Furthermore, in vitro studies have demonstrated that vitamin D may play an immune-modulatory role in human airway tissue through innate, adaptive immune pathways [16]. Notably, a recent trial of vitamin D supplementation in children with asthma did demonstrate improved asthma control such as reduced rates of exacerbations in those who received supplementation [17], suggesting that augmentation of $25-\mathrm{OH} \mathrm{D}$ levels could hold promise for future asthma health interventions.

Of studies that have examined the impact of vitamin D status on childhood asthma severity, there has not been much attention to black, inner-city populations, where rates of asthma-related hospitalizations are 2-3 times the national average (48 vs. 17 per 10,000) $[18,19]$. To better understand its significance in an inner-city pediatric population, we studied vitamin $\mathrm{D}$ status in a cohort of predominantly African-American preschool children with asthma in urban Baltimore. We sought to characterize the prevalence of $25-\mathrm{OH}$ vitamin D insufficiency, investigate if $25-\mathrm{OH}$ D levels are related to time spent outdoors, and prospectively evaluate the effect of vitamin $\mathrm{D}$ status on asthma morbidity.

\section{Subjects and methods Study design}

The Baltimore Indoor Environmental Study of Asthma in Kids was a longitudinal study designed to investigate the role of indoor pollutants and allergens on asthma. One hundred and fifty children with asthma ages 2 to 6 years of age were recruited. Serum 25-hydroxy vitamin D levels were measured at baseline, and health outcome information was collected from caregivers at baseline, 3 and 6 months. Procedures followed were in accordance with the ethical standards of the Johns Hopkins Medical Institutional Review Board, which approved the study, and caregivers of participants provided informed consent prior to enrollment.

\section{Participants}

Participating children were recruited from health systems providing care to most residents of East Baltimore (MD). Enrollment began September 2001 and the last patient follow-up was completed in April 2004. Potential subjects were first identified if they had a health care encounter assigned an ICD-9 (International Classification of Disease, 9th Revision) code of 493. X in the previous 12 months. They were confirmed as having asthma if they 1) had a physician diagnosis of asthma, and 2) had symptoms and/or medication use for asthma in the previous six months. All subjects maintained residence within one of nine contiguous ZIP codes within East Baltimore, which, based on 2000 US Census data, represents a geographic region that is $>99 \%$ urban. We excluded children with significant co-morbid conditions.

\section{Laboratory evaluation}

Blood drawn from children at the baseline evaluation was sent to the Johns Hopkins General Clinical Research Center labs for measurement of total 25-hydroxy vitamin D by radioimmunoassay (RIA) kit (DiaSorin, Stillwater, $\mathrm{MN})$. The intra- and inter-assay coefficients of variation for vitamin D were 5.19 and 7.90 , respectively. The preferred indicator of vitamin $\mathrm{D}$ status and the predominant circulating form is 25-OH D [20]. Serum 25-OH levels were stratified in the following brackets: $\leq 20,21-30$, and $>30 \mathrm{ng} / \mathrm{mL}$, and defined as deficient, insufficient, and sufficient, respectively, according to previously established guidelines for bone health $[20,21]$ (in the absence of consensus regarding appropriate levels for endocrine and extra-endocrine health) and levels below $15 \mathrm{ng} / \mathrm{ml}$ considered to impart higher risk for rickets [10]. Serum IgE levels, were also measured (ImmunoCAP, Phadia, Uppsala, Sweden).

\section{Clinical evaluation}

At an initial visit, children underwent allergy skin testing with a panel of 14 aero-allergens: American and German cockroach, dust mite mix, cat dander, dog hair/dander, mouse epithelia, rat epithelia, three pollens (Eastern Oak mix, grass mix, ragweed mix) and four molds (Helminthosporium, Alternaria, Penicillum, and Aspergillus). Atopy was defined as at least one positive skin test result, defined as a wheal size greater than a glycerin control of $\geq 2 \mathrm{~mm}$.

Evaluation of asthma morbidity was obtained at each time point from a health questionnaire completed by caregivers, which included close-ended questions derived from standard asthma symptoms questions used in prior studies of inner-city children with asthma [22]. We asked caregivers about acute health care use in the prior 3 months (emergency department visits, unscheduled doctor visits, and hospitalizations). We also collected information regarding the number of days (0-14) each child had the following symptoms in the previous 2 weeks: 1 ) wheezing, cough or tightness in the chest; 2 ) the need to slow down or stop activities because of 
asthma symptoms; 3) wheezing so badly that the child could only speak one or two words at a time between breaths; 4) cough without a cold or flu; 5) symptoms with exercise; and 6) nocturnal symptoms. Outdoor exposure was quantified both from questions regarding each child's average number of daily outdoor hours across each season and a prospective daily time-activity diary completed by caregivers during the study.

\section{Statistical analysis}

The 25-OH D levels in this population were summarized with means and proportions. Differences in vitamin D levels were compared across 4 seasons using the Kruskal-Wallis test for non-normally distributed continuous variables. Symptom-free days in a 2 -week period were calculated at baseline, 3 , and 6 months by subtracting the number of days of reported asthma symptoms from 14 days. Negative binomial regression with generalizing estimating equations [23] accounting for repeated measures was used to determine the relationship between baseline 25-OH D levels and the mean number of days of asthma symptoms across three time points. We constructed multivariate models accounting for age, gender, and socioeconomic factors. P values of less than 0.05 were considered statistically significant. All analyses were performed using StataSE software (Stata 11.0, College Station, Tx).

\section{Results}

We had sufficient serum to analyze 25-OH D for 121 of the 150 subjects. This subset did not differ demographically from the parent cohort. The children were predominantly African-American (91\%) and from households of low economic status. The majority of children (69\%) was atopic and had active asthma symptoms, with $62 \%$ meeting criteria for persistent asthma (Table 1).

\section{Levels of vitamin $\mathrm{D}$ measured in this population}

The median (IQR) serum 25-OH D level was $28 \mathrm{ng} / \mathrm{mL}$ (21-37). Fifty-four percent of subjects were found to be insufficient or deficient, with levels below the accepted sufficient cut-off of $30 \mathrm{ng} / \mathrm{mL}$, and $23 \%$ in the deficient range with serum levels of $20 \mathrm{ng} / \mathrm{mL}$ or below (Figure 1). About $7.4 \%$ of all subjects had $25-\mathrm{OH} \mathrm{D}$ levels in the range associated with the risk of rickets $(<15 \mathrm{ng} / \mathrm{mL})$. Vitamin D levels for the small number of whites tended to be higher despite equivalent socio-economic status (white vs. African-American: median 38 vs. $28 \mathrm{ng} / \mathrm{mL}, \mathrm{p}=0.07$ ).

\section{Effect of hours spent outdoors on 25-OH vitamin D levels} On average, children in our cohort spent 3 out of 24 hours outdoors daily (IQR $2-4$ hours). Time spent outdoors did not differ by gender (girls vs. boys: mean 3.1 vs. 3.2 hours). There was no association between the reported average daily hours spent outdoors and baseline 25-OH D levels $(\mathrm{p}=0.49)$ (Figure 2). It is worth noting, though, that none of the 121 children who spent more than 5 hours per day outside was $25-\mathrm{OH} \mathrm{D}$ deficient.

\section{Effect of season on 25-OH vitamin D levels}

Samples of blood were distributed evenly with regard to the season in which they were drawn (winter, 25; spring,

Table 1 Baseline characteristics of study participants by serum 25-OH vitamin D concentration

\begin{tabular}{|c|c|c|c|c|c|}
\hline \multirow[t]{2}{*}{ Characteristic } & \multirow{2}{*}{$\begin{array}{l}\text { All children } \\
(\mathrm{n}=121)\end{array}$} & \multicolumn{3}{|c|}{ Vitamin D level } & \multirow[t]{2}{*}{$P$ value } \\
\hline & & $\begin{array}{c}\text { Deficient }(<=20) \\
n=28(23 \%)\end{array}$ & $\begin{array}{l}\text { Insufficient (21-29 ng/mL) } \\
n=37(32 \%)\end{array}$ & $\begin{array}{l}\text { Sufficient (> }=30 \mathrm{ng} / \mathrm{mL}) \\
n=56(45 \%)\end{array}$ & \\
\hline Age (y) mean (range) & $4.4(2-6)$ & $4.5(2-6)$ & $4.9(2-6)$ & $4.1(2-6)$ & 0.06 \\
\hline Male sex $[n(\%)]$ & $73(60)$ & $17(61)$ & $23(62)$ & $33(59)$ & 0.84 \\
\hline Black race $[\mathrm{n}(\%)]$ & $109(90)$ & $28(100)$ & $33(89)$ & $48(86)$ & 0.05 \\
\hline BMI $\left(\mathrm{kg} / \mathrm{m}^{2}\right)$ & $17.8(4.1)$ & $17.9(4.7)$ & $18.7(5.7)$ & $17.2(2.1)$ & 0.85 \\
\hline Public health insurance $[\mathrm{n}(\%)](\mathrm{n}=118)$ & $106(90)$ & $21(78)$ & $34(94)$ & $51(93)$ & 0.07 \\
\hline $\begin{array}{l}\text { Household income less than } \$ 15,000 / y r \\
{[n(\%)](n=62)}\end{array}$ & $34(55)$ & $9(64)$ & $10(59)$ & $15(48)$ & 0.49 \\
\hline Caregiver a high school graduate [n (\%)] & $76(63)$ & $19(68)$ & $22(59)$ & $35(63)$ & 0.62 \\
\hline Atopic [n (\%)] $(\mathrm{n}=120)$ & $83(69)$ & $21(78)$ & $22(59)$ & $40(71)$ & 0.79 \\
\hline $\begin{array}{l}\text { Number of positive skin tests (mean } \pm \text { SD) } \\
(n=120)\end{array}$ & $2.71 \pm 2.91$ & $2.89 \pm 2.39$ & $2.38 \pm 2.77$ & $2.84 \pm 3.25$ & 0.66 \\
\hline \multicolumn{6}{|l|}{ Acute care in the past 3 months [n (\%)] } \\
\hline Emergency department visit & $28(23)$ & $6(21)$ & $9(24)$ & $13(23)$ & 0.89 \\
\hline Hospitalization & $4(3)$ & $0(-)$ & $1(3)$ & $3(5)$ & 0.19 \\
\hline Unscheduled doctor visit & $22(18)$ & $6(21)$ & $6(16)$ & $10(19)$ & 0.75 \\
\hline
\end{tabular}




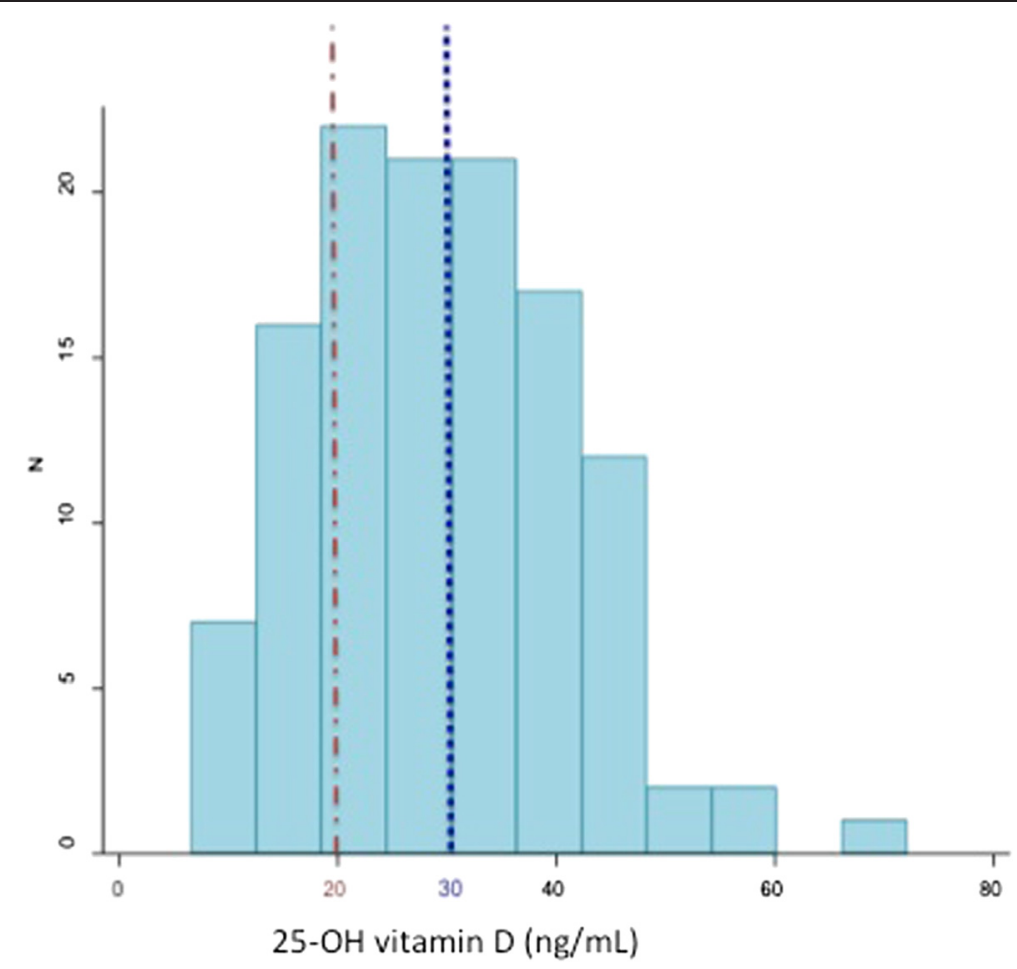

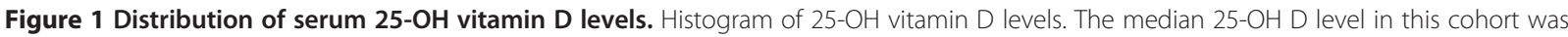
$28 \mathrm{ng} / \mathrm{mL}$ (IQR 21-37). The majority (54\%) of children had levels below current guidelines of sufficiency (30 ng/mL) (dotted line), with almost a quarter $(23 \%)$ in the deficient $(\leq 20 \mathrm{ng} / \mathrm{mL}$ ) range (dashed line).

35; summer, 26; fall, 33). There was no observed difference in serum $25-\mathrm{OH}$ D levels among the seasons $(\mathrm{p}=0.66)$ (Figure 3). When stratified by season of assessment, there was no association between serum 25-OH D levels and the outdoor time spent by each child in that same season (data not shown).

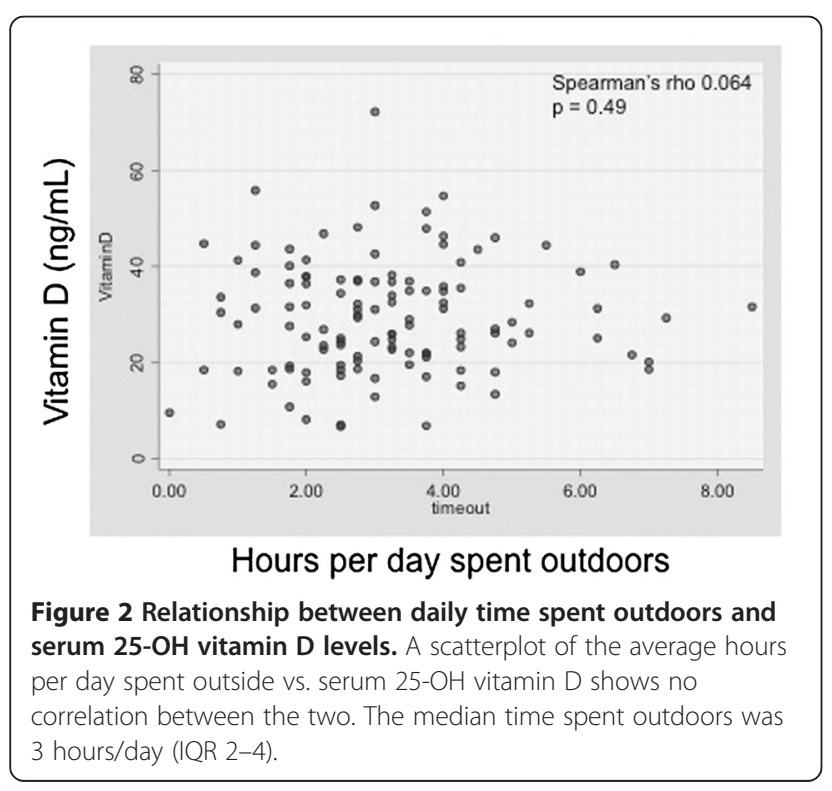

\section{Effect of vitamin $D$ levels on asthma indicators}

There was a modest, statistically significant inverse correlation between 25-OH D levels and total IgE concentrations (Spearman's rho $=-0.24 ; \mathrm{p}=0.03$ ). There was no association between $25-\mathrm{OH}$ D levels and atopic status as defined by positive skin testing $(\mathrm{p}=0.87)$, nor was there a significant correlation between $25-\mathrm{OH}$ D level and the

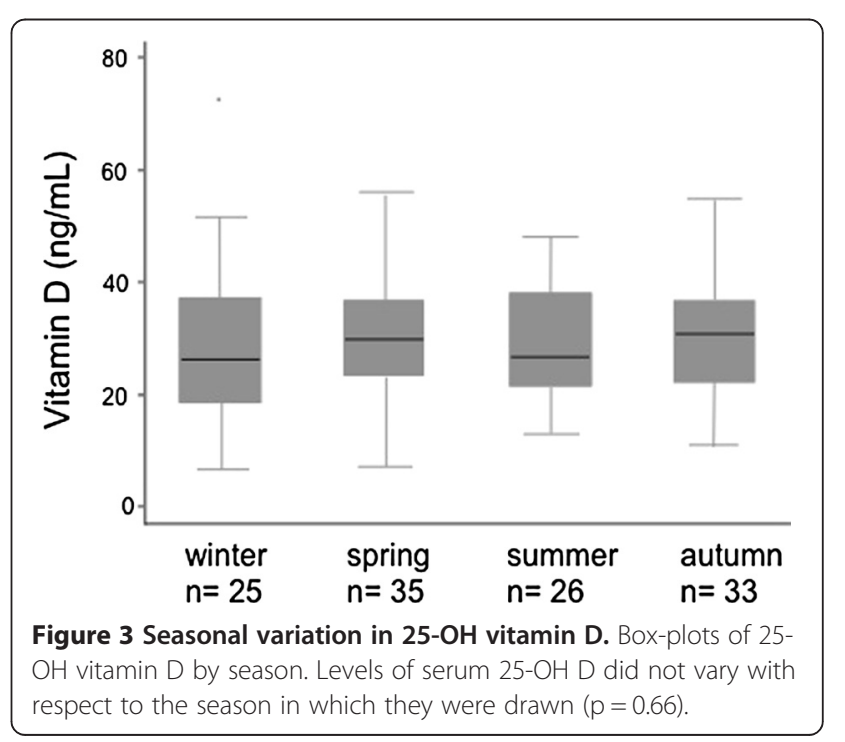


number of positive skin tests (Spearman's rho $=-0.0026$; $\mathrm{p}=0.98$ ). Additionally, there was no association between 25-OH D levels and acute health care visits (Table 1). In multivariate regression models, controlling for age, sex, and education level, asthma symptoms (cough without a cold or flu, cough/wheeze/chest tightness, and occurring with exercise) tended to be reduced with higher $25-\mathrm{OH}$ $\mathrm{D}$ levels, though the associations were not significant.

\section{Discussion}

This study demonstrated that $25-\mathrm{OH}$ vitamin $\mathrm{D}$ insufficiency is present in the majority of a cohort of urban, preschool-aged inner-city children with asthma. These findings extend those seen in heterogeneous populations of older children $[12,13]$ to a population of predominantly African-American children 2-6 years of age. Even at this early preschool age, 25-OH D levels were already strikingly below the recommended range, as defined by current guidelines for bone health. Over half (55\%) were either insufficient or deficient, and a disturbing proportion of children $(7 \%)$ in our cohort were at the extreme end of deficiency, with levels as low as those seen with rickets $(<15 \mathrm{ng} / \mathrm{mL})$. The implications of these findings may be even greater in younger cohorts, as it is during early childhood when considerable lung growth is still occurring, and when the respiratory system may be particularly sensitive to nutritional and environmental signals that induce changes in lung function [24].

Our findings are comparable to the NHANES 20012004 study of US children (age 1-21 years), where nine percent of all children had levels less than $15 \mathrm{ng} / \mathrm{mL}$, and sixty-one percent had levels in the range between 15 and $29 \mathrm{ng} / \mathrm{mL}$ [5]. In fact, within our defined geographical area of inner city Baltimore, 25-OH D levels are much lower among African-Americans than whites, identifying black preschool children as preferentially at risk for $25-\mathrm{OH} \mathrm{D}$ deficiency. Recent recommendations from the Institute of Medicine have challenged the traditional cut-offs for 25-OH D, suggesting that levels above $20 \mathrm{ng} / \mathrm{mL}$ instead of $30 \mathrm{ng} / \mathrm{mL}$ should be considered sufficient [25]. If we consider that suggested threshold, almost a quarter of subjects in our cohort would still be considered deficient. It is still uncertain what levels constitute sufficiency in asthma and other conditions apart from bone health; nevertheless, regardless of which guidelines are used to determine the optimal $25-\mathrm{OH}$ vitamin D level, our study demonstrates that Baltimore, with one of the highest rates of asthma, is representative of a greater national epidemic of 25-OH D insufficiency in black children.

The findings from this study suggest that, although UV light is necessary for dermal vitamin D production, black urban children with asthma appear to be unresponsive to what little daily sunlight they do receive, as higher daily levels of outdoor exposure were not linked to higher $25-\mathrm{OH}$ D. A limited number of other studies have also examined the relationship between sun exposure and $25-\mathrm{OH} \mathrm{D}$, but little attention has been paid to this relationship in children, particularly AfricanAmericans with asthma. Our study is unique in that it investigates this relationship between outdoor exposure and vitamin $\mathrm{D}$ status in a predominantly black population of preschool children, a group that includes children with the nation's highest levels of asthma. In prior studies of healthy people, controlled UVB exposure increased serum 25-OH D in a dose-related manner [26,27]; however, African-Americans and Caucasians have a notable difference in this dose response. Scragg and Camargo demonstrated that in a racially-mixed population, non-Hispanic blacks had only modest increases in 25-OH D with increasing outdoor activity when compared to the dramatic changes observed in whites, with changes in serum $25-\mathrm{OH}$ D observed only in response to extreme frequencies of outdoor activity (> 31 times in the past month) [28]. Taken with our findings, we conclude that cutaneous synthesis alone during limited outdoor exposure is not sufficient to raise serum levels effectively in black urban children. Exposure to sunlight beyond this range may cross a threshold where $25-\mathrm{OH} \mathrm{D}$ production begins to increase, as previous studies have shown that in healthy adults, higher doses of artificial UV are needed in darker-skinned individuals to measurably raise 25-OH D levels, compared those with lighter-skin [26]. However, a true prescription for natural UV exposure to achieve sufficient serum levels in black asthmatic children is yet to be determined.

Similarly, the predominantly African-American children in our study did not show any variation in $25-\mathrm{OH}$ D levels with respect to season, in contrast to prior studies of predominantly-Caucasian populations whose levels are lowest in winter and highest in summer [29]. The observed differences in African-Africans may reflect a blunted response to the varying sunlight availability across seasons due to the diminished capacity of darker skin to synthesize vitamin $\mathrm{D}$. We hypothesize that the lack of improvement in vitamin D status with increasing sun exposure-whether over a period of a day or across seasons-is a feature of increased skin pigmentation compounded by sub-optimal sun exposure. Spending a modest amount of additional time outside in regions with similar UV light availability is not likely an effective strategy to improve vitamin D status. On the other hand, promoting extreme doses of exposure, which may eventually lead to an improvement in levels, may not be practical or desired due to other risks of UV exposure. Alternative strategies to ensure adequacy through an enriched diet or dietary supplementation $[8,30]$ may be necessary to compensate for such deficiencies. 
Finally, our study supplements the small number of observational studies that show an association between personal 25-OH D and allergy and asthma morbidity [12-15,31]. Within our population, those children with lower 25-OH D levels had higher IgE levels. This inverse association has been shown previously [12], adding support to an allergy-mediated mechanism behind vitamin D's effects. Furthermore, higher 25-OH D levels tended to be protective against asthma symptoms, including wheezing/coughing/chest tightness, symptoms while exercising, and cough without a cold or flu, although associations were not statistically significant. More studies, including those that are designed to address causal links, are needed to solidify a link between asthma outcomes and low 25-OH D levels. The 2011 Institute of Medicine review of the literature regarding dietary requirements of calcium and vitamin D concluded that there was insufficient evidence to inform recommendations on intake for extra-skeletal outcomes, and that further trials were needed to assess the benefit of supplementation on extra-skeletal health [25]. If found to be significant, improving individual vitamin $\mathrm{D}$ status could help protect against common urban asthma triggers in vulnerable children and result in a sustainable decrease in asthma morbidity.

One limitation of our study is that it was conducted at a single site in an urban area at a specific solar zenith angle, which typically receives less UV radiation than more equatorial regions of the world. However, it appears that astronomical factors may be less influential in determining vitamin $\mathrm{D}$ status, given that studies conducted in latitudes with higher UV radiation (e.g., Costa Rica, Georgia, Arizona) [12,32,33] show surprisingly similar rates of deficiency. Rather, lifestyle and behavioral factors may be more significant in an increasingly urbanized world. While our study did not record sunscreen use or protective clothing, or allow for direct measures of UV exposure which could vary with time of day and weather conditions, more generalizable features such as time spent outdoors and skin pigmentation may instead be the key determinants of vitamin D status and, in turn, asthma control. Additionally, rates of vitamin D supplementation and dietary intake of D-rich foods were not specifically assessed here. Finally, as with most other studies investigating vitamin D's role in asthma, our design was cross-sectional, thus limiting our ability to establish a causal link between vitamin D and asthma morbidity. Future clinical trials are necessary to determine if vitamin $\mathrm{D}$ truly has the effects upon asthma health suggested by this observational literature.

\section{Conclusions}

Our study showed that vitamin D insufficiency is common in highly affected African-American preschool-aged children with asthma, and that increases within the range of time typically spent outdoors by urban children would not be an effective strategy for repletion. Our results also add to the accumulating evidence of a link between lower 25-OH vitamin D levels and the allergic/ asthmatic phenotype. Together, these findings offer that a combination of limitations in sunlight exposure and darker pigmentation may amplify the risk of vitamin D deficiency among black urban children, contributing to greater asthma morbidity than their white counterparts. Clinical trials are needed to determine whether augmentation of serum levels can attenuate asthma morbidity, and our results suggest that such trials may need to rely on dietary supplementation.

\section{Abbreviations}

25-OH D: 25-hydroxyvitamin D; ng/mL: Nanograms per milliliter; NHANES: National health and nutrition examination survey; UV: Ultraviolet.

\section{Competing interest}

The authors declare that they have no competing interests.

\section{Authors' contribution}

$\mathrm{SB}, \mathrm{PB}$, and RR contributed to the design of the study questions and $\mathrm{SB}$ drafted the manuscript. MCM, NNH, EM, GD participated in the design of the study and contributed to the preparation of the manuscript. RP and JCB participated in the statistical analysis and interpretation. All authors read and approved the final manuscript.

\section{Acknowledgements}

This work was presented in abstract form at the American Thoracic Society International Conference; May 15-19, 2010; New Orleans, LA.

This research was supported by the NIEHS (PO1 ES 09606; P50 ES 015903) and U.S. EPA (PO1 R-826724), and the Johns Hopkins NIEHS Center in Urban Environmental Health (P30 ES 03819).

\section{Financial disclosures}

The authors have indicated that they have no financial relationships relevant to this article to disclose.

\section{Author details}

${ }^{1}$ Johns Hopkins University, Baltimore, MD 21205, USA. ${ }^{2}$ University of South Carolina, Columbia, SC, USA.

Received: 11 December 2012 Accepted: 23 May 2013

Published: 12 June 2013

\section{References}

1. National center for health statistics, national center for health statisticsFASTATS. ; 2006. http://www.cdc.gov/nchs/fastats/asthma.htm.

2. Aligne CA, Auinger $P$, Byrd RS, Weitzman M: Risk factors for pediatric asthma. Contributions of poverty, race, and urban residence. Am J Respir Crit Care Med 2000, 162:873-877.

3. Ginde AA, Liu MC, Camargo CA Jr: Demographic differences and trends of vitamin D insufficiency in the US population 1988-2004. Arch Intern Med 2009, 169:626-632.

4. Saintonge S, Bang H, Gerber LM: Implications of a new definition of vitamin $D$ deficiency in a multiracial US adolescent population: the national health and nutrition examination survey III. Pediatrics 2009, 123:797-803.

5. Kumar J, Muntner P, Kaskel FJ, Hailpern SM, Melamed ML: Prevalence and associations of 25-hydroxyvitamin D deficiency in US children: NHANES 2001-2004. Pediatrics 2009, 124:362-370.

6. Webb AR: Who, what, where and when-influences on cutaneous vitamin D synthesis. Prog Biophys Mol Biol 2006, 92:17-25. 
7. Calvo MS, Whiting SJ, Barton CN: Vitamin D fortification in the united states and Canada: current status and data needs. Am J Clin Nutr 2004, 80(6 Suppl):1710S-1716S

8. Moore CE, Murphy MM, Holick MF: Vitamin D intakes by children and adults in the United States differ among ethnic groups. J Nutr 2005, 135:2478-2485.

9. Klepeis NE, Nelson WC, Ott WR, Robinson JP, Tsang AM, Switzer P, Behar JV, Hern SC, Engelmann WH: The national human activity pattern survey (NHAPS): a resource for assessing exposure to environmental pollutants. J Expo Anal Environ Epidemiol 2001, 11:231-252.

10. Holick MF: Resurrection of vitamin D deficiency and rickets. J Clin Invest 2006, 116:2062-2067.

11. Holick MF: Vitamin D deficiency. N Engl J Med 2007, 357:266-281.

12. Brehm JM, Celedon JC, Soto-Quiros ME, Avila L, Hunninghake GM, Forno E, et al: Serum vitamin D levels and markers of severity of childhood asthma in Costa Rica. Am J Respir Crit Care Med 2009, 179:765-771.

13. Brehm JM, Schuemann B, Fuhlbrigge AL, Hollis BW, Strunk RC, Zeiger RS, et al: Serum vitamin D levels and severe asthma exacerbations in the childhood asthma management program study. J Allergy Clin Immunol 2010, 126:52-58.

14. Searing DA, Zhang Y, Murphy JR, Hauk PJ, Goleva E, Leung DY: Decreased serum vitamin $D$ levels in children with asthma are associated with increased corticosteroid use. J Allergy Clin Immunol 2010, 125:995-1000.

15. Sutherland ER, Goleva E, Jackson LP, Stevens AD, Leung DY: Vitamin D levels, lung function, and steroid response in adult asthma. Am J Respir Crit Care Med 2010, 181:699-704.

16. Litonjua AA: Childhood asthma may be a consequence of vitamin D deficiency. Curr Opin Allergy Clin Immunol 2009, 9:202-207.

17. Majak P, Olszowiec-Chlebna M, Smejda K, Stelmach I: Vitamin D supplementation in children may prevent asthma exacerbation triggered by acute respiratory infection. J Allergy Clin Immunol 2011, 127:1294-1296.

18. CDC Asthma prevalence, health care use and mortality: United States, 2003-05, 2010. http://www.cdc.gov/nchs/data/hestat/asthma03-05/asthma03-05.htm.

19. Maryland asthma control program. Asthma profile, Baltimore city. 2009; 2009 http://fha.dhmh.maryland.gov/mch/documents/asthma_control/ Profile_BaltimoreCity.pdf.

20. Holick MF: Vitamin D status: measurement, interpretation, and clinical application. Ann Epidemiol 2009, 19:73-78.

21. Bischoff-Ferrari HA, Giovannucci E, Willett WC, Dietrich T, Dawson-Hughes B: Estimation of optimal serum concentrations of 25 -hydroxyvitamin D for multiple health outcomes. Am J Clin Nutr 2006, 84:18-28.

22. Morgan W, Crain EF, Gruchalla RS, O'Connor GT, Kattan M, 3rd Evans R, Stout J, Malindzak G, Smartt E, Plaut M, Walter M, Vaughn B, Mitchell H, Inner-City Asthma Study Group: Results of a home-based environmental intervention among children with asthma. NEJM 2004, 351:1058-1080.

23. Diggle $P$, Heagerty $P$, Liang K, Zeger S: Analysis of longitudinal data. 2nd edition. Oxford, England: Oxford University Press; 2002.

24. Dezateux C, Stocks J: Lung development and early origins of childhood respiratory illness. Br Med Bull 1997, 53:40-57.

25. Institute of Medicine: Dietary reference intakes for calcium and vitamin D. Washington, DC: The National Academies Press; 2011.

26. Armas LA, Dowell S, Akhter M, Duthuluru S, Huerter C, Hollis BW, Lund B, Heaney RP: Ultraviolet- $B$ radiation increases serum 25 -hydroxyvitamin $D$ levels: The effect of UVB dose and skin color. J Am Acad Dermatol 2007 57:588-593.

27. Chen TC, Chimeh F, Lu Z, Mathieu J, Person KS, Zhang A, Kohn N, Martinello S, Berkowitz R, Holick MF: Factors that influence the cutaneous synthesis and dietary sources of vitamin D. Arch Biochem Biophys 2007, 460:213-217.

28. Scragg R, Camargo CA Jr: Frequency of leisure-time physical activity and serum 25-hydroxyvitamin D levels in the US population: Results from the third national health and nutrition examination survey. Am J Epidemiol 2008, 168:577,86. discussion 587-91.

29. Stryd RP, Gilbertson TJ, Brunden MN: A seasonal variation study of 25- hydroxyvitamin D3 serum levels in normal humans. J Clin Endocrinol Metab 1979, 48:771-775.

30. Harris SS: Vitamin D and African Americans. J Nutr 2006, 136:1126-1129.

31. Freishtat RJ, labal SF, Pillai DK, Klein CJ, Ryan LM, Benton AS, Teach SJ: High prevalence of vitamin D deficiency among inner-city African American youth with asthma in Washington, DC. J Pediatr 2010, 156:948-952.
32. Cole CR, Grant FK, Tangpricha V, Swaby-Ellis ED, Smith JL, Jacques A, Chen $H$, Schleicher RL, Ziegler TR: 25-hydroxyvitamin D status of healthy, low-income, minority children in Atlanta, Georgia. Pediatrics 2010, 125:633-639.

33. Jacobs ET, Alberts DS, Foote JA, Green SB, Hollis BW, Yu Z, Martinez ME: Vitamin D insufficiency in southern Arizona. Am J Clin Nutr 2008, 87:608-613.

doi:10.1186/1475-2891-12-81

Cite this article as: Bose et al:: Outdoor exposure and vitamin D levels in urban children with asthma. Nutrition Journal 2013 12:81.

\section{Submit your next manuscript to BioMed Central and take full advantage of:}

- Convenient online submission

- Thorough peer review

- No space constraints or color figure charges

- Immediate publication on acceptance

- Inclusion in PubMed, CAS, Scopus and Google Scholar

- Research which is freely available for redistribution

Submit your manuscript at www.biomedcentral.com/submit
C) Biomed Central 